\title{
Infection prevalence, intensity, and tissue damage caused by the parasitic flatworm, Bdelloura candida, in the American horseshoe crab (Limulus polyphemus)
}

Christopher J Brianik ( $\square$ cjb238@scarletmail.rutgers.edu )

Stony Brook University School of Marine and Atmospheric Sciences

Justin Bopp

Michigan State University

Camilla Piechocki

Stony Brook University School of Marine and Atmospheric Sciences

Nancy Liang

Stony Brook University School of Marine and Atmospheric Sciences

Sabrina O'Reilly

Stony Brook University School of Marine and Atmospheric Sciences

Robert M. Cerrato

Stony Brook University School of Marine and Atmospheric Sciences

Bassem Allam

Stony Brook University School of Marine and Atmospheric Sciences

\section{Research Article}

Keywords: gill, adult, cocoon, candida, infection, horseshoe

Posted Date: September 3rd, 2021

DOl: https://doi.org/10.21203/rs.3.rs-842746/v1

License: (a) (i) This work is licensed under a Creative Commons Attribution 4.0 International License.

Read Full License 


\section{Abstract}

Parasite infection dynamics can have profound implications on a host's fitness; yet, there is a dearth of information on parasites in the American horseshoe crab (Limulus polyphemus) (Linnaeus 1758), a species that has experienced population declines in recent decades. Therefore, we aimed to quantify the prevalence, intensity, and gill surface area coverage of the ectoparasitic flatworm (cocoon and adult stages), Bdelloura candida in adult $(n=29)$, sub-adult $(n=7)$ and juvenile $(n=32)$ horseshoe crabs collected from Moriches Bay, NY $\left(40.7810^{\circ} \mathrm{N}, 72.7171^{\circ} \mathrm{W}\right)$ in 2019 and 2020 . Subsamples of horseshoe crab gill tissue $(10 \%)$ were collected from live specimen, then $B$. candida cocoons were enumerated across the gill subsamples using microscopy while the extent of tissue damage was quantified with histology. B. candida was present in all adult and sub-adult crabs (100\%), whereas juveniles exhibited $6.2 \%$ prevalence. Cocoon intensities per sample ranged from 28 to 805 cocoons, with $4.0-94.0 \%$ of gill lamellae harboring cocoons. In infected individuals, the total cocoon surface area coverage on gill tissues ranged from $0.06-14.51 \%$, with higher cocoon intensities observed in the ventral-most gill quartiles relative to the dorsal-most gill regions. Sex was strongly supported as a primary driver behind $B$. candida infection intensities with adult females harboring higher intensities. Among infected gill lamellae, cocoon intensity was lower in mitochondrial-rich regions relative to mitochondrial-poor regions. These results provide novel insight into $B$. candida infection dynamics across horseshoe crab demographics, but further research is necessary to quantify the physiological impacts of the infection on L. polyphemus.

\section{Introduction}

The American horseshoe crab (Limulus polyphemus) is an iconic marine arthropod species that has persisted $\sim 445$ million years (Rudkin et al. 2008) and plays critical ecological roles in coastal marine systems from Maine, USA to the Yucatan peninsula in Mexico (Botton 2009; Smith et al. 2017). These ecological roles include bioturbation (sediment irrigation), structural habitat for epibionts, predation on marine bivalves and benthic macrofauna (Botton and Ropes 1987; Botton et al. 2003), and these animals provide a critical food source for migratory shorebirds, such as the endangered red knot (Calidris canutus rufa) (Tsipoura and Burger 1999; Smith et al. 2017). In addition to their numerous ecological roles, horseshoe crabs are an important human health and economic resource. The blood of horseshoe crabs serves to extract a unique compound, Limulus amebocyte lysate, (referred to as LAL) that is used to detect the presence of endotoxins from gram-negative bacteria in human medical supplies, and this practice has resulted in a threefold increase in biomedical harvest since the 1980s (Eyler et al. 2015; Smith et al. 2017). Moreover, roughly 1-2 million crabs are exploited annually for bait in the whelk and eel fishery throughout the US East Coast (ASMFC 2019). Exploitation from these industries has been perceived to be the primary contributor towards their recent coastwide declines, and thus, led to their "Vulnerable" conservation status in the US (Smith et al. 2016). Despite the current management interest, the impacts of biotic stressors (e.g. parasite infections) on horseshoe crab fitness and population dynamics have rarely been addressed, as management strategies have primarily focused on direct 
anthropogenic exploitation. In particular, there is a dearth of information in regard to the role host-parasite relationships play on horseshoe crab fitness.

Parasites are ubiquitous in nature with most wild animals harboring at least a mild infection, with the prevalence and intensity frequently increasing with size, age, and density of the host (Zelmer et al 1998). As established stressors, parasites are capable of influencing numerous aspects of their host's biology including survival, fecundity, population cycles, and behavior (Lehman 1993; Hudson et al. 1998; Tompkins and Bergon 1999; Ebert et al. 2000; Poulin 2010) with cascading impacts on the entire ecosystem. Although variable between species, mild parasite intensities are typically well tolerated by a host (e.g. pinworm in humans) (Lehman 1993; Stjernman et al. 2008); however, intense infections can exacerbate this relationship, leading to adverse outcomes for a host. For instance, infections by roundworm (Ascaris lumbricoides) in the human intestine are considered to be mildly symptomatic, but the mere presence of several worms can cause blockages leading to indirect intestinal damage (Despommier et al. 2020). Similar observations have been made in aquatic animals, as many Monogenea (commonly observed ectoparasites of fish and amphibians) have been observed to damage their host not through resource exploitation, but via their attachment organs that penetrate the epithelial layer leading to excess mucus production and inflammation (Whittington 2005). Moreover, parasites infecting gill tissue have been demonstrated to adversely impact survival of aquatic organisms exposed to oxygen-poor conditions (Molnar 1994), with oxygen carrying capacity reduced up to $50 \%$ in crustaceans and fish (Taylor et al. 1996). Although several internal parasitic symbionts have been recorded in horseshoe crabs (Leibovitz and Lewbart 2003), the basic information on external parasites (i.e. prevalence, intensity and associated physiological impacts) such as the flatworm, Bdelloura candida, are not well established in the horseshoe crab literature.

B. candida is a $2 \mathrm{~cm}$ long triclad flatworm that is an obligate parasite of the American horseshoe crab. Adult worms are primarily located on the walking appendages and book gills, while the cocoons are attached on the inner surface of the gill lamellae by means of an endplate (Sluys 1989). Histological sampling has revealed that cocoons of triclad worms can cause necrosis of surrounding gill tissue (Groff and Leibovitz 1982; Leibovitz and Lewbart 2003). Moreover, few studies have quantified the extent of $B$. candida damage within gill tissue, which could be expansive. For example, Leibovitz and Lewbart (2003) documented over 50 B. candida cocoons can be attached to a single gill lamella in adult horseshoe crabs; albeit, their low sample size ( $<9$ adult horseshoe crab specimens) provided limited inferences about $B$. candida infection dynamics in horseshoe crab populations. Despite the limited knowledge surrounding $B$. candida infection, $B$. candida have been observed throughout the entire range of the American horseshoe crab (Riesgo et al. 2017). Although these studies have provided insight into $B$. candida infection characteristics, information pertaining to $B$. candida prevalence, intensities, and their coverage on horseshoe crab gills remains missing.

In this study, juvenile, sub-adult, and adult American horseshoe crabs were sampled from an estuary along the south shore of Long Island, New York, to better understand B. candida infection dynamics. The dida intensity and prevalence across horseshoe 
crab demographics (age groups and sex) and 2) investigate intrinsic factors that explain B. candida intensities in horseshoe crabs. Additionally, we examined pathology inflicted by cocoons on horseshoe crab gill tissue via histological analysis and quantified the percentage of gill tissue occupied by $B$. candida cocoons. We also assessed the infection intensity across the vertical gill space to determine if infection intensity was random (homogenous) or aggregated (heterogenous) across horseshoe crab gill space (ventral most or dorsal most). Lastly, we enumerated the proportion of $B$. candida cocoons occupying the central- mitochondrial rich area (CMRA) vs. peripheral mitochondrial-poor area (PMPA) of each gill lamellae (Hans et al. 2018) to determine if there was a spatial preference for cocoon presence across these regions that provide different waste and respirational roles (Hans et al. 2018). This study provides novel insight into the infection dynamics of $B$. candida on horseshoe crabs and could serve as the basis of monitoring ectoparasite infection in wild horseshoe crab populations.

\section{Materials \& Methods}

\section{Sample collection}

On 24 June, 2019, juvenile (instars $8-10 ; n=30)$ and adult $(n=29)$ horseshoe crabs were randomly collected at Pikes Beach, Moriches Bay, Long Island, NY $\left(40.77^{\circ} \mathrm{N},-72.71^{\circ} \mathrm{W} ;\right.$ Fig. 1). Juvenile crabs between instars 8-10 (prosomal width range $=41.4 \mathrm{~mm}-57.9 \mathrm{~mm}$ ) (Sekiguchi 1988; Carmichael et al. 2003) were hand collected haphazardly along a 500 meter transect at the water's edge ( $<0.5 \mathrm{~m}$ depth), then transported back to the lab where they were euthanized using an overdose of Tricaine-S (MS-222) and frozen at $-20^{\circ} \mathrm{C}$ for long term storage. Adults (prosomal width range $=188.0 \mathrm{~mm}-283.0 \mathrm{~mm}$ ) were collected from the intertidal zone ( 0.5-1 $\mathrm{m}$ deep) shortly before high tide and were temporarily placed in fish totes filled with ambient seawater. Sex, prosomal width, and weight were recorded for every individual. Sex was determined by the presence of modified pedipalps, weight was measured using a Pesola (Schindellegi, Switzerland) $10 \mathrm{~kg}( \pm 0.3 \%)$ spring scale, and prosomal width was measured to the nearest millimeter using Vernalier calipers. The gills of adult crabs were subsampled by removing the upper-right portion of book gills, which constituted approximately $10 \%$ of their gills (Fig. 2). Both gill samples and B. candida samples were individually stored in $70 \%$ ethanol to be counted at a later time. After sample collection, all adult crabs were released immediately back to the water.

Opportunistic samples of L. polyphemus were obtained from a trawl survey in September-October 2020 from muddy habitat $\left(\sim 2 \mathrm{~m}\right.$ depth) and intertidal beaches of Moriches Bay $\left(40.79^{\circ} \mathrm{N},-72.71^{\circ} \mathrm{W}\right)$. This sample was comprised of 2 juveniles $(n=2$; instars $9 \& 10$; prosomal width range $=40.5 \mathrm{~mm}-57.2 \mathrm{~mm})$ and a sub-adult cohort $(n=7$; instars $14-18$; prosomal width range $=113.0 \mathrm{~mm}-179.0 \mathrm{~mm})$. Gill samples from these crabs were not removed, but instead were carefully examined for the presence of $B$. candida cocoons and adult worms.

To obtain B. candida adult intensity in a standardized format, forceps were used to remove B. candida worms from the book gills and legs over a timed 5-minute period immediately following the physical 
approach was implemented for two reasons: 1) every adult flatworm could not be accurately removed from the adults by hand or by brief freshwater rinses and 2) we wanted to minimize the desiccation stress to horseshoe crabs during sampling. All adult worms collected during each 5-minute sampling period were stored in $30 \mathrm{ml}$ of $70 \%$ ethanol in $50 \mathrm{~mL}$ Falcon conical centrifuge tubes and were processed later in the lab. Prevalence of $B$. candida was determined by tallying the presence of either adult worms or cocoons on horseshoe crab gill tissues or other appendages. Population prevalence was determined as the percentage of individuals that were infected by $B$. candida.

\section{B. candida intensity measurements}

To measure adult flatworm intensity, collected adult flatworms were counted and recounted under a dissecting microscope by three readers. Samples were randomly chosen, and readers were blinded from previous recorded intensities in the same sample to minimize bias. The final intensity count was determined if two or more observers had the same intensity counts. If all counts differed between readers in a sample, a fourth reader counted the sample to finalize intensity based on agreement with another reader. Intensity was defined as the total count of adult $B$. candida.

To measure the intensity of $B$. candida cocoons, each individual lamella was removed from the book gill subset. $B$. candida cocoons were enumerated under the dissecting microscope for each gill lamella in each gill sample subset. The intensity of cocoons was also enumerated separately on the central mitochondria-rich area (CMRA) and the peripheral mitochondria-poor area (PMPA) of the lamellae. Figure 2 visually illustrates CMRA and PMPA delineations.

\section{Gill and cocoon surface area preparations and measurements}

After measuring cocoon intensity, each lamella was placed on a lightbox with a ruler and photographed using a digital Panasonic LUMIX DMC-T380 waterproof camera. Every gill subset was sampled from the ventral to the dorsal side. However, lamella measuring less than $1 \mathrm{~cm}$ in diameter (typically the first few in the book gill) at its widest point were not photographed as they were not observed to harbor any infections and their small size contributed little to total respiratory surface area. One gill sample deteriorated during processing and could not be analyzed.

To measure the proportion of gill surface area covered by the cocoons, cocoon area and gill lamella surface area were measured using ImageJ (version 1.8.0) software (Schneider et al. 2012). The local threshold tool was used to automatically detect and measure the surface area of the cocoons against the lamella, which limited human error. In cases where the color threshold inadequately distinguished cocoons or lamella from each other, manual measurements were made in ImageJ. Average cocoon size was determined by randomly sampling 100 cocoon measurements across all individual adult crabs.

\section{Histological analysis}


A small gill sample $(\sim 2 \mathrm{~cm} \times 1 \mathrm{~cm} \times .5 \mathrm{~cm})$ from a horseshoe crab, not used in the other analyses, was removed and placed in a histo-cassette then fixed in $10 \%$ buffered formalin, and embedded in paraffin wax. Heavily infected sections of lamellae were selected to ensure the detection of $B$. candida cocoons. Sections $(\sim 5 \mu \mathrm{m})$ were mounted on slides and stained with Harris's haematoxylin and Eosin. Multiple slides were cut from the same paraffin block, and slides were visually inspected for any signs of pathology, such as inflammation, necrosis or encapsulation.

\section{Statistical analyses}

A generalized linear model (GLM) was employed to determine which intrinsic factors explained the most variance behind cocoon intensity in adult horseshoe crab gill tissues. Only crabs sampled in 2019 were included in the statistical analyses because only prevalence was evaluated in the opportunistically sampled crabs in 2020. The response variable was cocoon intensity, and the explanatory variables were adult flatworm intensities, total gill surface area, and sex in the GLM. Prior to constructing the model, cocoon intensity data were fit to Poisson and negative binomial error structures and each distribution was compared by Akaike's information criterion (AIC) in the fitdistrplus R package (Delignette-Muller and Dutang 2015; R version 4.0.2, R Core Development Team 2020) to determine the most appropriate error structure given the data. In all GLMs, multicollinearity between the explanatory variables was assessed by calculating the variance inflation factor (VIF) in the Performance R package (Lüdecke et al. 2020). Variables with a VIF greater than 5 were removed from the GLM, as VIFs above 5 are considered to be moderately or strongly correlated with each other and strong correlations between one or more predictor variables can lead to erroneous and biased estimates (Gareth et al. 2013). Given that size is a sexually dimorphic trait in all horseshoe crab populations (Smith et al. 2009; Bopp et al. 2019) and it had the largest VIF in both GLMs, size was not included as an explanatory variable in the global models for cocoon and adult flatworm intensity candidate sets. Outside of size, other explanatory variable VIFs were $<3$ and were therefore, not removed from the global model prior to fitting and model selection analysis. The fit of all possible GLM model variants was assessed with the dredge function in the MuMin $\mathrm{R}$ package (Barton and Barton 2015). Inference was drawn from models within each GLM candidate set using the small sample size corrected Akaike Information Criteria (AICC) and AIC weights (Burnham and Anderson 2002). Model variants with $\triangle \mathrm{AICC}<2$ and $\mathrm{AIC}$ weights $>0.10$ were considered to have moderate support (Burnham and Anderson 2002).

A separate GLM was constructed to examine the relationship between adult flatworm intensity and the explanatory variables total gill surface area, sex, and horseshoe crab size. Similar to the other GLM, negative binomial and Poisson error distributions were fit to adult flatworm intensity data and were assessed with AIC. As aforementioned, the multicollinearity analysis was repeated, eliminating size, and model selection was again carried out using the dredge function.

To determine if intensity was homogenous or aggregated across gill tissue space (ventral to dorsal sections), each individual crab's gill subsets were split into four quartile groups and the total cocoon intensity for each gill quartile was summed. A Friedman rank-sum test was used to determine if 
unreplicated blocks, while gill quartiles were considered groups in the Friedman model. If intensities differed between gill quartile groups in the Friedman test, multiple pairwise comparisons between the quartile groups were examined using a post-hoc Conover-Iman test (Conover and Iman 1979). A Bonferroni correction was used to control for multiple comparisons with an assumed familywise error

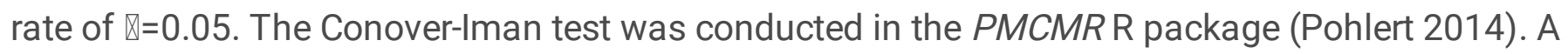
Spearman rank correlation test was also employed between the quartile group with the highest cocoon intensity (4th quartile) and the total cocoon intensity across gill samples to determine if the most infected gill quartile could serve as a relative proxy of overall cocoon infection intensity.

To determine if $B$. candida cocoons were spaced randomly or preferentially across mitochondrial regions of the lamellae in infected individuals, we calculated the average proportion of cocoons on CMRA regions vs. PMPA regions. Each of these regions can be assessed visually given their contrasting pigmentation on gill lamellae (Fig. 2C; Hans et al. 2018). Additionally, in order to determine if cocoon placement was proportional to the coverage of CMRA and PMPA regions within gill lamellae, CMRA regions of 100 random lamellae were randomly measured using ImageJ. Moreover, we employed a beta regression model (Ferrari and Cribari-Neto 2004) to determine if total cocoon intensities influenced the proportions of cocoons on the CMRA regions. A beta regression accounts for the fact that proportions are bound between 0 and 1, and error variances are not normally distributed. In the model, cocoon CMRA proportion was the dependent variable, and the total cocoon intensity was the independent variable. Beta regression models were fit using maximum likelihood estimation in the betareg package in $\mathrm{R}$ (Cribari-Neto and Zeilas 2010).

\section{Results}

\section{Prevalence and intensity}

From the horseshoe crabs collected in June 2019, B. candida infections (both adult worms and cocoons) were present in $100 \%$ of adult gill samples $(n=29)$, while only 1 juvenile (instars $8-11)$ from this collection date $(n=30)$ was observed to harbor any signs of infection (3 cocoons). The opportunistic samples procured in October of 2020 , showed a similar pattern with $100 \%$ of sub-adults $(n=7$; instars 16-18) being observed to have either adult worms and/or cocoons. Of note, the two juveniles obtained in 2020 (i.e instars 9-11) were the least infected relative to all adults/sub-adults with one having no signs of infection and the other having a single cocoon. From the infected adult crabs, both cocoon intensity and adult worm counts varied considerably, as intensities of cocoons and flatworms ranged from 37 to 805 (mean $=267 \pm 41 \mathrm{SE}$ ) and 5 to $196(58 \pm 9 \mathrm{SE})$, respectively. Adult female horseshoe crabs had an average of $306 \pm 42$ SE cocoons; whereas, males had a lower average cocoon intensity ( $85 \pm 5$ SE cocoons). Mean infection count was $3.2 \pm 0.50$ SE cocoons per lamella; however, total intensity varied across two orders of magnitude, ranging from 0.4 to 12.2 cocoons per lamella. Total number of gill lamellae ( $>1 \mathrm{~cm}$ diameter) also varied between crabs with counts ranging from 53 to 125 with an average of $91 \pm 3$ SE. Cocoon surface area differed by four orders of magnitude among adult crabs, covering

Loading [MathJax]/jax/output/CommonHTML/fonts/TeX/fontdata.js gill subsamples), with $2.3 \% \pm 0.6 \% \mathrm{SE}$ 
representing the average (Fig. 3). The proportion of cocoons occupying the CMRA regions ranged from 0.05 to 0.53 ( $x=0.21 \pm 0.02 \mathrm{SE}$ ) in infected adult horseshoe crabs (Fig. 4).

\section{Microscopic analysis}

B. candida cocoons were elliptical in shape with an anchor shape protrusion extending from one side, and they were attached to the lamellae epithelium via a cement-like excretion that surrounded the cocoon body and the anchor (Figs. 5C-D). After randomly sampling 100 single cocoons, the average cocoon area was $3.37 \pm 0.07 \mathrm{SE} \mathrm{mm} \mathrm{mm}^{2}$. Histological observations showed healthy horseshoe crab leaflets consisted of parallel lamellae connected via pillar cells, with space between the pillars believed to be vascular channels (Fig. 5A). The dorsal tips of the leaflets were covered in a thickened proteinaceous matrix (Fig. S1), which also covered the epithelium of the leaflets, albeit not as thick as the blunted dorsal tips (Fig. 5A). Mats of bacteria and algae also frequently covered sections of gill epithelium but were superficial and not observed to cause any inflammation (Fig. 5A). Surface defects that impacted the organization of epithelial tissue and disrupted the typical gill structure were observed in histology sections of infected lamellae with melanization frequently observed on the outer layer of these lesions (Fig. 5E). Granulomas were frequently observed in the vascular lumen of the lamellae causing hemocyte aggregation, encapsulation and inflammation (Figs. 5B, E-F).

\section{Generalized linear model: cocoon intensity}

The negative binomial distribution was chosen for the cocoon intensity GLM, as the AIC was lowest for the negative binomial distribution relative to the Poisson distribution ( $\triangle$ AIC 4673.7). Therefore, a negative binomial was used as the family error structure in the candidate model set. The GLM model selection process revealed that three out of 8 model variants had moderate support (cumulative AIC weight $>0.88$ ) according to $\triangle \mathrm{AIC}$ values and AIC weights (Table 1). Adult flatworm intensity was supported in all three models, but the top model had support for gill surface area as well (Table 1). There was also some support for sex influencing cocoon intensities (model 3, Table 1). The evidence ratio of the top model relative to model three was $\sim 1.9$ (Table 1 ), suggesting that the top model is nearly 2 times more probable than model 3. However, model selection uncertainty was present between the top three models given $\triangle \mathrm{AIC}<2$ (Table 1). 
Table 1

Candidate model results for generalized linear model (GLM) for the cocoon intensity of adult horseshoe crabs after model fitting with the dredge package in R. A total of 8 possible model combinations were assessed, but only models with moderate support (Akaike weight $>0.10$ and $\triangle \mathrm{AlCc}<2$ ) are shown here (see Methods) and are ranked by AICc. The cumulative Akaike weight between these models comprised 0.88 . The global model included sex, adult worm intensity, and gill surface area, as explanatory variables with cocoon intensity set as the response variable. NP represents the number of parameters. The negative binomial distribution was the family error structure used in the GLM, as AIC was lower for the negative binomial distribution relative to the Poisson distribution ( $\triangle$ AIC 4673.7).

\begin{tabular}{|c|c|c|c|c|c|c|}
\hline $\begin{array}{l}\text { Model } \\
\text { Number }\end{array}$ & Model & NP & $\begin{array}{l}\text { Log } \\
\text { Likelihood }\end{array}$ & AlCc & $\triangle \mathrm{AlCc}$ & $\begin{array}{l}\text { Akaike } \\
\text { weight }\end{array}$ \\
\hline 1 & $\begin{array}{l}\text { cocoon intensity adult intensity + gill } \\
\text { surface area }\end{array}$ & 4 & -181.5 & 372.8 & 0 & 0.37 \\
\hline 2 & cocoon intensity $\sim$ adult intensity & 3 & -183.1 & 373.1 & 0.3 & 0.32 \\
\hline 3 & cocoon intensity $\sim$ adult intensity + sex & 5 & -180.7 & 374.0 & 1.2 & 0.20 \\
\hline 4 & $\begin{array}{l}\text { cocoon intensity } \sim \text { adult intensity }+ \text { sex } \\
+ \text { gill surface area }\end{array}$ & 6 & -180.1 & 375.9 & 3.1 & 0.08 \\
\hline 5 & cocoon intensity $\sim$ gill surface area & 3 & -186.6 & 380.2 & 7.4 & 0.01 \\
\hline 6 & cocoon intensity $\sim$ sex & 4 & -185.4 & 380.4 & 7.6 & 0.01 \\
\hline 7 & $\begin{array}{l}\text { cocoon intensity } \sim \text { sex }+ \text { gill surface } \\
\text { area }\end{array}$ & 5 & -184.0 & 380.7 & 7.9 & 0.01 \\
\hline 8 & cocoon intensity $\sim 1$ & 2 & -189.8 & 384.1 & 11.3 & 0.00 \\
\hline
\end{tabular}

\section{Generalized linear model: adult worm intensity}

The negative binomial distribution was used as the family error structure in the GLM given it was a better fit $(A I C=293.9)$ compared to the Poisson distribution $(A I C=1166.2)$. Model selection revealed that 3 out of 4 possible model variants relating adult flatworm intensity to covariates had moderate to strong support (Table 2) with model selection uncertainty present. The top model only included sex and had an evidence ratio of $\sim 3$ relative to models 2 and 3 , indicating this model is nearly 3 times more probable compared to the other models. Model support for gill surface area (models 2 and 3 ) was weaker compared to sex in terms of affecting adult flatworm intensities (Table 2). 
Table 2

Candidate model results for generalized linear model (GLM) for the adult worm intensity of adult horseshoe crabs after model fitting with the dredge package in R. A total of 4 possible model combinations were assessed, but only models with moderate support (Akaike weight $>0.10$ ) are presented and are ranked by AICc. The cumulative Akaike weight between these models comprised 0.88 . The global model included sex and gill surface area as explanatory variables with adult intensity set as the response variable. NP represents number of parameters. The negative binomial distribution was used as the family error structure in the GLM given it was a better fit (AIC $=293.9)$ compared to the Poisson distribution (AIC = 1166.2).

\begin{tabular}{|llccccc|}
\hline $\begin{array}{l}\text { Model } \\
\text { Number }\end{array}$ & Model & NP & $\begin{array}{l}\text { Log } \\
\text { Likelihood }\end{array}$ & AlCc & AAICc & $\begin{array}{l}\text { Akaike } \\
\text { weight }\end{array}$ \\
\hline 1 & adult worm intensity sex & 4 & -140.7 & 291.2 & 0 & 0.56 \\
\hline 2 & $\begin{array}{l}\text { adult worm intensity } \sim \text { gill surface } \\
\text { area + sex }\end{array}$ & 5 & -140.5 & 293.6 & 2.4 & 0.17 \\
\hline 3 & $\begin{array}{l}\text { adult worm intensity } \sim \text { gill surface } \\
\text { area }\end{array}$ & 3 & -143.4 & 293.8 & 2.6 & 0.15 \\
\hline 4 & adult worm intensity 1 & 2 & -144.9 & 294.4 & 3.2 & 0.12 \\
\hline
\end{tabular}

\section{Spatial patterns of cocoon intensities}

Cocoon infection intensity differed among gill lamellae quartiles (Friedman-test; $F_{3,84}=76.82, p<0.001$ ). Specifically, cocoon intensities were different between all quartile group pairwise comparisons (Table 3). Gill quartile 4 (ventral most) had higher cocoon intensities relative to all other gill quartiles (Fig. 6). Gill quartile 4 exhibited a strong positive correlation (Spearman; $\rho=0.96, p=<0.001$ ) with overall infection intensity in the gill subsample (Fig. 7). 
Table 3

Post-hoc pairwise Conover-Iman comparison results among the four gill quartile groups following the Friedman test. Quartiles 1 and 4 denote the dorsal-most and ventral-most gill quartiles, respectively. $V$ represents the Conover-Iman test statistic. The p-adjusted value represents the Bonferroni corrected $p$-value to minimize the inflation of familywise type 1 error. Padjusted values $<0.05$ denote statistical significance.

\begin{tabular}{|lll|}
\hline Quartile comparison & $\mathbf{V}$ & p adjusted \\
\hline 1 to 2 & 12.54 & $<0.01$ \\
\hline 1 to 3 & 25.09 & $<0.001$ \\
\hline 1 to 4 & 29.00 & $<0.001$ \\
\hline 2 to 3 & 12.54 & $<0.01$ \\
\hline 2 to 4 & 16.45 & $<0.001$ \\
\hline 3 to 4 & 3.90 & $<0.01$ \\
\hline SUPPLEMENTAL & & \\
\hline Figure S1. Histological cross-section of the acellular blunted lamella tips \\
\hline
\end{tabular}

\section{Cocoon intensity on CMRA vs. PMPA}

Total cocoon intensity appeared to weakly explain some of the variation behind the proportion of cocoons in the CMRA regions in adult horseshoe crab gill lamellae with cocoons more likely to occupy the CMRA regions with increasing infection intensity (beta regression; pseudo $R^{2}=0.14, p=0.046, d f=26$, coefficient $=0.001$ ). The average proportion of cocoons occupying the CMRA region of gill lamellae was $21.0 \% \pm 2.0 \% \mathrm{SE}$. Out of the 100 random lamellae measurements, the average proportion of the CMRA region vs. total gill area was $30.6 \% \pm 0.6 \% \mathrm{SE}$.

\section{Discussion}

This study demonstrates that $B$. candida infections are highly prevalent among adult horseshoe crabs, and that the cocoons of this parasite are capable of occupying a considerable amount of gill real estate $(>10 \%)$. To our knowledge, the only previous studies evaluating $B$. candida infection intensities demonstrated that adult horseshoe crabs had $400-800$ (average $=575, n=4$ ) cocoons across their entire gill area (Pearse 1949) and are capable of having $>50$ cocoons within a single gill lamella (Leibovitz and Lewbart 2003). In contrast, the average $B$. Candida intensity was 267 in this study within our subsamples ( $10 \%$ of the total horseshoe crab gill area), and assuming that $B$. candida cocoon intensity patterns in the remaining $90 \%$ of the gill are homogenous, our results indicate average cocoon intensities could be much higher (average of 2,670 cocoons in entire gill space). Interestingly, cocoon prevalence and intensity were not uniform across life history stages, as only $6.2 \%(n=2)$ of juvenile crabs (instars $<13 ; 58 \mathrm{~mm}$ ) had 
adult worms. Moreover, all cocoon intensities were orders of magnitude higher on adult crabs than juveniles (when present). Ontogenetic shifts in parasite infrapopulation characteristics, such as the one we observed here, are not uncommon for a species where both prevalence and infection intensities increase with host body size and age. However, the mechanisms leading to the adult-juvenile dichotomy in B. candida prevalence observed is intriguing, as juvenile (instar groups 8-10) and adult crabs share the same habitat (spawning beaches) during the spring months possibly exposing the juvenile crabs to the parasite. Moreover, the high (100\%) prevalence of $B$. candida in adult crabs suggests that $B$. candida is well adapted at colonizing a susceptible host with transmission unlikely to be limiting to juveniles; therefore, these age-group prevalence trends may presumably be a result of behavioral, foraging, or physiological differences between the stages.

A possible explanation for the ontogenetic differences in infection are due to the decrease in molting frequency observed in horseshoe crabs as they age. Juvenile horseshoe crabs molt several times a year until reaching instar $10(49.2 \mathrm{~mm})$, after which molting occurs annually until a terminal molt is reached upon sexual maturation (Carmichael et al. 2003, Estes et al. 2015). Following the terminal molt, the accumulation of epibionts on horseshoe crabs (slipper snails, barnacles, macroalgae, etc.) are well documented (Walls et al. 2002) with similar dynamics likely to influence the establishment of B. candida. For example, the antiparasitic effects of molting have been observed in Antarctic krill (Euphausia superba), as recently molted krill had $0 \%$ prevalence of ectoparasites as opposed to pre-molt individuals that had a $66 \%$ prevalence (Tarling and Cuzin-Roudy 2008). Moreover, this study also found parasite prevalence increased with host age, presumably a result of decreased molting frequency. Further support of molting as a mechanism of parasitic defense was demonstrated in Daphnia magna, as molting was found to limit the adhesion of bacteria and subsequent infection (Duneau and Ebert 2012). Similarly, prevalence and intensity of epizootic shell disease in the American lobster were shown to increase in animals with lower molting frequencies (egg-bearing females) and this was suggested to result from the inability of infected lobsters to eliminate pathogenic microbes during molting (Castro et al. 2012). Although molting seems to be a likely mechanism in $B$. candida regulation, it is difficult to test, as the most heavily infected cohort (adults) rarely molt and are difficult to maintain in laboratory conditions in sufficient numbers to test such a hypothesis.

Outside of molting, other phenomena such as horseshoe crab behavior, ontogenetic differences in size, physiology and resource use may explain prevalence dynamics across age groups. For instance, it is possible that $B$. candida is sexually transmitted and initiates infection during the extensive copulatory process observed in horseshoe crabs in which multiple males may attach to one female for days to months each spring (Brockmann and Penn 1992). However, the observation of $100 \%$ prevalence infections among the sub-adults $(n=7$, instars $16-18)$ in this study makes this an unlikely scenario, as this age group exhibits different space-use patterns relative to adults, and they do not engage in mating behavior (Rudloe et al 1981). Differences in gill surface area between instars 8-10 and sub-adults/adults may also be a primary factor behind prevalence disparities, as parasite intensity can correlate with increasing body size such is the case with Salmon louse (Lepeophtheirus salmonis) infecting Atlantic 
reducing space competition among conspecific ectoparasites. Additionally, the body size argument may also explain why horseshoe crab sex was a contributing factor in $B$. candida infection rates because adult females are larger than males (Loveland and Botton 1992) and thus, females have more available surface area or "habitat" for $B$. candida to reside. However, host size has not been found to be a limiting factor in ectoparasite infection intensities in some organisms; whereas, host whole body metabolism can be a more important determinant of ectoparasite intensities (Hechinger et al. 2019) because host energy can be more constraining to parasite infection loads.

The difference in infection intensities among age groups may partially reflect contrasting foraging behaviors among life history stages and may make the juvenile cohort ( $<12$ instars) unsuitable for $B$. candida establishment. For example, $B$. candida is believed to indirectly consume food particle remnants from horseshoe crab feeding activities (Jennings 1977). Juvenile crabs (instars $<10$ ) predominantly rely on sedimentary organic matter and meiofauna adjacent to salt-marsh habitats (Botton et al. 2003b); in contrast, older juvenile and adult crabs predominantly forage on larger-bodied prey, such as bivalves and polychaetes (i.e. Neries spp.) (Botton and Ropes 1987; Gaines et al. 2002). Therefore, the nutritional resources on juvenile horseshoe crabs may not be sufficient or optimal for $B$. candida's nutritional requirements. However, the theory of $B$. candida foraging on remnants of horseshoe crab prey items remains controversial due to chemical analysis indicating that $B$. candida may obtain some nutritional energy directly from horseshoe crabs (Lauer and Fried 1977). The application of modern techniques to assess resource-use, such as stable isotope analysis (bulk or compound-specific), could be used to resolve this controversy, as it could identify the nutritional resources adult $B$. candida predominantly relies on.

Given that this study emphasized one population of horseshoe crab hosts, we cannot state these infection intensity patterns apply to other populations, as other factors such as biogeographic differences in reproduction ratios, environmental conditions, migration patterns, abundance, and size may result in varying $B$. candida. For example, host population density is often positively correlated with ectoparasite intensity as a result of increased probability of direct transmission (e.g. contact, breeding, etc.) among conspecifics within a population after controlling for other covariates (Arneberg et al. 1998). However, controversy surrounds the contribution of population density to increased parasite infection intensities. Bagge et al. (2004) noted that the primary determinant behind infection rate variability for multiple Monogenean species' in crucian carp (Carrasius carassius) was host population size, presumably due to a required infection density threshold for effective transmission, and thus numbers of hosts were the limiting transmission factor. For horseshoe crabs, size-at-maturation and population densities are the largest in Mid-Atlantic populations (Delaware and Chesapeake Bays) and can be 2-400 times greater than their northern counterparts (Shuster 1955; James-Pirri 2005; Smith et al. 2009, 2017 ). In turn, B. candida intensity may contrast between host populations due to both disparate population densities, abundances, and body size differences of $L$. polyphemus. Previous studies have demonstrated that ectoparasite intensities increase with host body size in a variety of animal species, including chigger parasites on the Spiny lizard (Sceloporus clarkii,) (Watkins and Blouin-Demers 2019), multiple species of Woodpeckers Loading [MathJax]/jax/output/CommonHTML/fonts/TeX/fontdata.js n Brook trout (Salvelinus fontinalis) (Poulin et 
al. 1991). Therefore, assessing B. candida population dynamics between horseshoe crab populations with different characteristics (e.g. abundance, density, etc.) may be beneficial for elucidating mechanisms that regulate ectoparasite- host relationships, particularly in such an ancient and stable host species.

Within an individual host or even an organ, parasites are known to aggregate in regions that provide the best niche for them and in turn higher fitness, this was observed in the cocoons of $B$. candida in this study as cocoons of were significantly more prevalent in the dorsal most quartile of gill lamellae (Fig. 6). The ventral most gills were preferentially used for cocoon placement, possibly due to the larger size of these lamellae as larger lamellae size not only provides more habitat, but also allows cocoon location to be away further from edge of the lamellae sheltering the cocoons from excessive flow, a critical concern for ectoparasites (Wootten 1974). Additionally, larger lamellae can pump more water, which may be necessary to meet the oxygen demand of the flatworm cocoons which require oxygen to sclerotize (Huggins and Waite 1993). Unsurprisingly, the realized niche of a parasite is frequently smaller than the potential niche (Sukhdeo and Croll 1981), resulting from constraints on attachment, competition and nutrient acquisition, factors that can lead to hyper specialization within a larger organ. For example, the gills of fish are often segregated between parasites such as Monogenean flatworms or parasitic copepods which will localize to particular gill arches in fish (Arme and Halton 1972; Teemer et al. 2020). Similar results were observed in this study as $B$. candida cocoons were infrequently placed in the CMRA's, a specialized zone of the lamellae important for nitrogenous waste excretion (Henry et al. 1996; Hans et al. 2018). However, we postulate that cocoon placement is fairly random across the CMRA vs. PMPA sections of horseshoe crab gills because the CMRA region in this study comprised an average area of $0.30 \pm 0.60 \mathrm{SE}$ across the total gill surface while the average proportion of cocoons was $0.21 \pm 0.02 \mathrm{SE}$, indicating that the placement of $B$. candida cocoons is nearly proportional to the CMRA. It is important to note that, the CMRA cocoon placement was not entirely avoided in this study and the likelihood of CMRA cocoon placement appeared to slightly increase with cocoon intensity, albeit, the beta regression results indicated a weak relationship between overall cocoon intensity and the proportion of cocoons in the CMRA region. Therefore, in other horseshoe crab populations it is important to determine if the spatial arrangement (random or clustered) of cocoons on gill lamella varies across B. candida intensity levels.

The extent of the deleterious impacts imposed by $B$. candida infections remains uncertain; however, horseshoe crab fitness could be affected from the combination of anthropogenic and ambient environmental stressors coupled with $B$. candida infection. This study revealed no more than $15 \%$ of gill surface area in any adult was covered with $B$. candida cocoons, however this estimate is likely conservative as our analysis was unable to detect the cocoon cemented regions (Fig. 5C, D). Regardless of this potential underestimation, light infection intensities on gills from ectoparasites may have adverse impacts on horseshoe crab fitness. For example, ectoparasite coverage on gills appears to be directly proportional to reduction on the velocity of oxygen uptake in aquatic organisms (Duthie and Hughes 1987) and may potentially affect horseshoe crab fitness by reducing respiration efficiency, especially in hypoxic conditions. Hypoxic conditions are expected to become more chronic and frequent in coastal marine environments in the coming decades (Diaz and Rosenberg 2008), and the combined stress of $B$. 
hypoxic conditions ( $<2.0 \mathrm{O}^{2} \mathrm{mgL}^{-1}$ ) and parasitic nematode (Anguillicola crassus) infections over 4 days, eels with low swim bladder degenerative indexes $(0-1)$ and the highest infection loads exhibited shorter time until death (10-25 hours shorter on average) than their uninfected counterparts (Lefebvre et al. 2007). Additionally, horseshoe crabs face a unique and direct anthropogenic stressor, in the form of blood extraction for biomedical purposes, that may make individuals with intense infections of $B$. candida more susceptible to sublethal effects (i.e. reduced oxygen uptake, increased respiration energy expenditure, etc.) or mortality (Smith et al. 2017; Owings et al. 2019, 2020). The sublethal impacts of biomedical blood extraction on horseshoe crab survivors ( $70 \%$ survival) are numerous, such as a significant reduction in hemocyanin concentrations following typical blood volume extractions ( $30 \%$ blood volume) and reduced spawning frequency (Owings et al. 2019, 2020), and it can take up to 4 months for amebocytes to fully recover to baseline levels (Novitsky 1984). Hemocyanin is essential for maintaining oxygen transport (Mangum 1980), immune response (Coates et al. 2011), wound repair and molting (Adachi et al. 2005) and can be altered by environmental conditions (Coates et al. 2012). Additionally, these amebocytes are involved in the immunological response to $B$. candida cocoons (Fig. 5), so the impairment of these cells could reduce the crabs' ability to respond to immunological insults and/or increase baseline level of stress of these animals and potentially increasing susceptibility to stressors. Therefore, understanding the simultaneous impacts of projected intensifying environmental conditions (i.e. temperature, ocean acidification, and hypoxia), biomedical blood harvest on hemocyanin levels, and $B$. candida infections are required, as their combined effect may engender more severe consequences for horseshoe crabs than when these effects are isolated.

\section{Conclusions}

This study provides novel insight into $B$. candida infection characteristics across multiple life history stages of $L$. polyphemus, and the results suggest there is a moderate dichotomy of $B$. candida prevalence between instars $<12$ and sub-adult/adult crabs. This study also demonstrated that cocoon infection intensity and surface area coverage differed substantially in adults, indicating infection is considerably variable. This study only focused on one $L$. polyphemus population and patterns of $B$. candida infection may not be uniform across all horseshoe crab populations. Because parasite abundance can vary due to differences in geographical location, host density, ambient environmental characteristics, and distance between host populations (Poulin et al. 2011), future studies quantifying the $B$. candida intensity and prevalence across other geographically distinct horseshoe crab populations are needed. Additionally, other underlying mechanisms (i.e. horseshoe crab population density, age group composition, etc.) of $B$. candida infection dynamics should be addressed at the population level to understand both host-parasite ecology and the evolutionary underpinnings of $B$. candida infection. Monitoring $B$. candida infection in horseshoe crabs is recommended given that histological analysis indicated $B$. candida may adversely impact gill functioning and could adversely affect host fitness, especially if $B$. candida intensity is higher in populations outside of this study. Based on the findings, overall infection intensity strongly correlates with the $25 \%$ ventral-most gill lamellae (Fig. 6), and thus, monitoring programs could expedite intensity

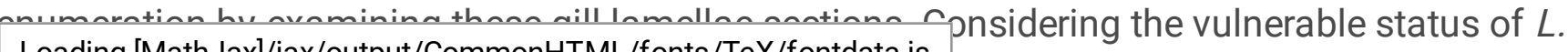


polyphemus in the U.S., the impact of $B$. candida infection on horseshoe crab respiration coupled with environmental stressors on survival should be examined to determine if this host-parasite relationship is contributing to recent population declines.

\section{Declarations}

\section{Acknowledgements}

The study was partially supported by the National Sea Grant College Program of NOAA to the Research Foundation of State University of New York on behalf of New York Sea Grant and the Ocean and Great Lakes Award through the New York State Department of Environmental Conservation. We thank Dr. Jan Lovy for providing feedback on Horseshoe crab gill histology photos. The authors have declared that no competing interests exist.

Funding: The Ocean and Great Lakes Award provided by the New York State Department of Environmental Conservation and NOAA New York Sea Grant.

Data availability: The datasets and code generated and analyzed during this study are available from the corresponding authors on request.

Competing interests: The authors declare no competing interests.

Ethics approval: organisms and tissue samples collected for this research were permitted through by the New York State Department of Conservation under the Scientific License to Collect \#1145 under the New York State Environmental Conservation Law.

Informed consent: No human subjects were used in this study and informed consent was, therefore, not applicable

\section{References}

1. Adachi K, Endo H, Watanabe T, Nishioka T, Hirata T (2005) Hemocyanin in the exoskeleton of crustaceans: enzymatic properties and immunolocalization. Pigment Cell Res 18(2):136-143

2. Arme C, Halton DW (1972) Observations on the occurrence of Diclidophora merlangi (Trematoda: Monogenea) on the gills of whiting, Gadus merlangus. J Fish Biol 4(1):27-32

3. Arneberg P, Skorping A, Grenfell B, Read AF (1998) Host densities as determinants of abundance in parasite communities. Proceedings of the Royal Society of London. Series B: Biological Sciences 265(1403):1283-1289

4. ASMFC (2019) 2019 horseshoe crab benchmark stock assessment and peer review report. Atlantic States Marine Fisheries Commission, Arlington

5. Bagge AM, Poulin R, Valtonen ET (2004) Fish population size, and not density, as the determining 
6. Barton K, Barton MK (2015) Package 'mumin'. Version 1(18):439

7. Bopp JJ, Sclafani M, Smith DR, McKown K, Sysak R, Cerrato RM (2019) Geographic-specific capture-recapture models reveal contrasting migration and survival rates of adult horseshoe crabs (Limulus polyphemus). Estuaries Coasts 42(6):1570-1585

8. Botton ML, Ropes JW (1987) Populations of horseshoe crabs, Limulus polyphemus, on the northwestern Atlantic continental shelf. Fish Bull 85(4):805-812

9. Botton ML, Shuster CN Jr, Keinath JA (2003a) Horseshoe crabs in a food web: who eats whom. The American Horseshoe Crab. Harvard University Press, Cambridge, pp.133-153

10. Botton ML, Loveland RE, Tiwari A (2003b) Distribution, abundance, and survivorship of young-of-theyear in a commercially exploited population of horseshoe crabs Limulus polyphemus. Mar Ecol Prog Ser 265:175-184

11. Botton ML (2009) The ecological importance of horseshoe crabs in estuarine and coastal communities: a review and speculative summary. In: Biology and conservation of horseshoe crabs. Springer, Boston

12. Brockmann HJ, Penn D (1992) Male mating tactics in the horseshoe crab, Limulus polyphemus. Anim Behav 44(4):653-665

13. Burnham KP, Anderson DR (2002) A practical information-theoretic approach. In: Model selection and multimodel inference. Springer, New York

14. Carmichael RH, Rutecki D, Valiela I (2003) Abundance and population structure of the Atlantic horseshoe crab Limulus polyphemus in Pleasant Bay, Cape Cod. Mar Ecol Prog Ser 246:225-239

15. Castro KM, Cobb JS, Gomez-Chiarri M, Tlusty M (2012) Epizootic shell disease in American lobsters Homarus americanus in southern New England: past, present and future. Diseases of Aquatic Organisms 100(2):149-158

16. Coates CJ, Kelly SM, Nairn J (2011) Possible role of phosphatidylserine-hemocyanin interaction in the innate immune response of Limulus polyphemus. Developmental Comparative Immunology 35(2):155-163

17. Coates CJ, Whalley T, Nairn J (2012) Phagocytic activity of Limulus polyphemus amebocytes in vitro. J Invertebr Pathol 111(3):205-210

18. Conover WJ, Iman RL (1979) On multiple-comparisons procedures. Los Alamos Sci. Lab. Tech. Rep. LA-7677-MS 1:14

19. Cribari-Neto F, Zeileis A (2010) Beta regression in R. Journal of statistical software 34(1):1-24

20. Delignette-Muller ML, Dutang C (2015) fitdistrplus: An R package for fitting distributions. Journal of statistical software 64(4):1-34

21. Despommier DD, Gwadz RW, Hotez PJ (2020) Parasitic diseases. Parasites Without Borders, Inc. NY, Springer. New York, pp 205-213

22. Diaz RJ, Rosenberg R (2008) Spreading dead zones and consequences for marine ecosystems. crienre 321(5891).926-920 
23. Drake A (2019) Body size predicts the likelihood of harbouring ectoparasites among channel catfish (Ictalurus punctatus) in Lac des Chats and its tributaries. University of Ottowa. Ottawa, Canada

24. Duneau D, Ebert D (2012) The role of moulting in parasite defence. Proceedings of the Royal Society B: Biological Sciences 279(1740):3049-3054

25. Duthie GG, Hughes GM (1987) The effects of reduced gill area and hyperoxia on the oxygen consumption and swimming speed of rainbow trout. Journal of experimental biology 127(1):349354

26. Ebert D, Lipsitch M, Mangin KL (2000) The effect of parasites on host population density and extinction: experimental epidemiology with Daphnia and six microparasites. Am Nat 156(5):459-477

27. Estes MG, Carmichael RH, Macdonald PD, Brady AJ, McFadyen J (2015) Molts reveal life-history patterns for juvenile American horseshoe crabs in fringe habitats. In: Changing Global Perspectives on Horseshoe Crab Biology, Conservation and Management. Springer, Cham, pp 255-278

28. Eyler S (2015) Review of the Atlantic States Marine Fisheries Commission Fishery Management Plan for horseshoe crab. Atlantic States Marine Fisheries Commission. Arlington, VA

29. Ferrari S, Cribari-Neto F (2004) Beta regression for modelling rates and proportions. Journal of applied statistics 31(7):799-815

30. Friedman M,. Correction A (1939) J Am Stat Assoc 34(205):109-109

31. Gaines EF, Carmichael RH, Grady SP, Valiela I (2002) Stable isotopic evidence for changing nutritional sources of juvenile horseshoe crabs. The Biological Bulletin 203(2):228-230

32. Galloway TD, Lamb RJ (2017) Abundance of chewing lice (Phthiraptera: Amblycera and Ischnocera) increases with the body size of their host woodpeckers and sapsuckers (Aves: Piciformes: Picidae). Can Entomol 149:473-481

33. Gareth J, Daniela W, Trevor H, Robert T (2013) An introduction to statistical learning: with applications in $R$. Spinger

34. Groff JF, Leibovitz L (1982) A gill disease of Limulus polyphemus associated with triclad turbellarid worm infections. Biol Bull 163:392

35. Hans S, Quijada-Rodriguez AR, Allen GJ, Onken H, Treberg JR, Weihrauch D (2018) Ammonia excretion and acid-base regulation in the American horseshoe crab, Limulus polyphemus. Journal of Experimental Biology 221(6)

36. Hechinger RF, Sheehan KL, Turner AV (2019) Metabolic theory of ecology successfully predicts distinct scaling of ectoparasite load on hosts. Proceedings of the Royal Society B 286(1917):2019 1777

37. Henry RP, Jackson SA, Mangum CP (1996) Ultrastructure and transport-related enzymes of the gills and coxal gland of the horseshoe crab Limulus polyphemus. The Biological Bulletin 191(2):241-250

38. Hudson PJ, Dobson AP, Newborn D (1998) Prevention of population cycles by parasite removal. science 282(5397):2256-2258 
39. Huggins LG, Waite JH (1993) Eggshell formation in Bdelloura candida, an ectoparasitic turbellarian of the horseshoe crab Limulus polyphemus. Journal of experimental Zoology 265(5):549-557

40. James-Pirri MJ, Tuxbury K, Marino S, Koch S (2005) Spawning densities, egg densities, size structure, and movement patterns of spawning horseshoe crabs, Limulus polyphemus, within four coastal embayments on Cape Cod, Massachusetts. Estuaries 28(2):296-313

41. Jennings JB (1977) Patterns of nutritional physiology in free-living and symbiotic Turbellaria and their implications for the evolution of entoparasitism in the phylum Platyhelminthes. Acta Zool Fennica 154(2):63-79

42. Lauer DM, Fried B (1977) Observations on nutrition of Bdelloura candida (Turbellaria), an ectocommensal of Limulus polyphemus (Xiphosura). American Midland Naturalist 240-247

43. Lefebvre F, Contournet P, Crivelli AJ (2007) Interaction between the severity of the infection by the nematode Anguillicola crassus and the tolerance to hypoxia in the European eel Anguilla anguilla. Acta Parasitologica 52(2):171-175

44. Lehmann T (1993) Ectoparasites: direct impact on host fitness. Parasitology today 9(1):8-13

45. Leibovitz L, Lewbart GA (2003) Diseases and symbionts: vulnerability despite tough shells. Shuster, CN, Barlow, RB \& Brockmann, HJ.The American Horseshoe Crab. Harvard University Press, Cambridge, pp 45-275

46. Linnaeus $C$ (1758) Systema naturae per regna tria naturae, secundum classes, ordines, genera, species, cum characteribus, differentiis, synonymis, locis. Tomus I. Editio decima, reformata. Holmiae (Salvius) 1(1-4):1-824

47. Loveland RE, Botton ML (1992) Size dimorphism and the mating system in horseshoe crabs Limulus polyphemis L. Anim Behav 44(5):907-916

48. Lüdecke M, Waggoner \& Patil (2020) Assessment of Regression Models Performance. CRAN. https://easystats.github.io/performance

49. Mangum CP (1980) Respiratory function of the hemocyanins. Am Zool 20(1):19-38

50. Molnar K (1994) Effect of decreased water oxygen content on common carp fry with Dactylogyrus vastator (Monogenea) infection of varying severity. Dis Aquat Organ 20:153-153

51. Novitsky TJ (1984) Discovery to commercialization-the blood of the Horseshoe-crab. Oceanus 27(1):13-18

52. Owings M, Chabot C, Watson III, W (2019) Effects of the biomedical bleeding process on the behavior of the American horseshoe crab, Limulus polyphemus, in its natural habitat. The Biological Bulletin 236(3):207-223

53. Owings M, Chabot C, Watson III, W., 2020. Effects of the biomedical bleeding process on the behavior and hemocyanin levels of the American horseshoe crab (Limulus polyphemus). Fishery Bulletin 118 (3)

54. Pearse AS (1949) Observations on flatworms and nemerteans collected at Beaufort, N. C. Proc. U. S. Nat. Mus. 100: 25-38

Loading [MathJax]/jax/output/CommonHTML/fonts/TeX/fontdata.js

Page 19/28 
55. Pohlert T (2014) The pairwise multiple comparison of mean ranks package (PMCMR). $R$ package 27(2020):10

56. Poulin R, Rau ME, Curtis MA (1991) Infection of brook trout fry, Salvelinus fontinalis, by ectoparasitic copepods: the role of host behaviour and initial parasite load. Anim Behav 41(3):467-476

57. Poulin R (2010) Parasite manipulation of host behavior: an update and frequently asked questions. Advances in the Study of Behavior 41:151-186

58. Poulin R, Blanar CA, Thieltges DW, Marcogliese DJ (2011) The biogeography of parasitism in sticklebacks: distance, habitat differences and the similarity in parasite occurrence and abundance. Ecography 34(4):540-551

59. R Core Development Team (2020) R: A language and environment for statistical

60. computing. R Foundation for Statistical Computing, Vienna, Austria. URL https://www.R-project.org/

61. Riesgo A, Burke EA, Laumer C, Giribet G (2017) Genetic variation and geographic differentiation in the marine triclad Bdelloura candida (Platyhelminthes, Tricladida, Maricola), ectocommensal on the American horseshoe crab Limulus polyphemus. Marine biology 164(5):111

62. Rudkin DM, Young GA, Nowlan GS (2008) The oldest horseshoe crab: a new xiphosurid from Late Ordovician Konservat-Lagerstätten deposits, Manitoba, Canada. Palaeontology 51(1):1-9

63. Rudloe A (1981) Aspects of the biology of juvenile horseshoe crabs, Limulus polyphemus. Bull Mar Sci 31(1):125-133

64. Schneider CA, Rasband WS, Eliceiri KW (2012) NIH Image to ImageJ: 25 years of image analysis. Nature methods 9(7):671-675

65. Sekiguchi K (1988) Biology of horseshoe crabs. Science House, Tokyo

66. Shuster CN Jr (1955) On morphometric and serological relationships within the Limulidae, with particular reference to Limulus polyphemus (L.). Ph.D Dissertation. New York, New York, New York University

67. Sluys R (1989) A monograph of the marine triclads. A.A. Balkema, Rotterdam, p 463

68. Sukhdeo MV, Croll NA (1981) The location of parasites within their hosts: factors affecting longitudinal distribution of Trichinella spiralis in the small intestine of mice. International journal for parasitology 11(2):163-168

69. Smith DR, Millard MJ, Carmichael RH (2009) Comparative status and assessment of Limulus polyphemus with emphasis on the New England and Delaware Bay populations. In: Biology and conservation of horseshoe crabs. Springer, Boston, pp 361-386

70. Smith DR, Brockmann HJ, Beekey MA, King TL, Millard MJ, Zaldivar-Rae J (2017) Conservation status of the American horseshoe crab, (Limulus polyphemus): a regional assessment. Rev Fish Biol Fisheries 27(1):135-175

71. Stjernman M, Råberg L, Nilsson J (2008) Maximum host survival at intermediate parasite infection intensities. PLoS One 3(6):2463 
72. Tarling GA, Cuzin-Roudy J (2008) External parasite infestation depends on moult frequency and age in Antarctic krill (Euphausia superba). Polar Biol 31(2):121-130

73. Taylor AC, Field RH, Parslow-Williams PJ (1996) The effects of Hematodinium sp.-infection on aspects of the respiratory physiology of the Norway lobster, Nephrops norvegicus (L.). J Exp Mar Biol Ecol 207(1-2):217-228

74. Teemer SR, de Buron I, Gacula CV, Sparkes TC (2020) Microhabitat preference, body size, and egg allocation in the gill parasite Naobranchia lizae (Copepoda). Parasitol Res 119(4):1237-1242

75. Tompkins DM, Begon M (1999) Parasites can regulate wildlife populations. Parasitology today 15(8):311-313

76. Tsipoura N, Burger J (1999) Shorebird diet during spring migration stopover on Delaware Bay. Condor, 635-644

77. Tucker CS, Sommerville C, Wootten R (2002) Does size really matter? Effects of fish surface area on the settlement and initial survival of Lepeophtheirus salmonis, an ectoparasite of Atlantic salmon Salmo salar. Dis Aquat Organ 49(2):145-152

78. Walls EA, Berkson J, Smith SA (2002) The horseshoe crab, Limulus polyphemus: 200 million years of existence, 100 years of study. Rev Fish Sci 10(1):39-73

79. Watkins HV, Blouin-Demers G (2019) Body size, not age, predicts parasite load in Clark's Spiny Lizards (Sceloporus clarkii). Can J Zool 97(3):220-224

80. Whittington ID (2005) Monogenea Monopisthocotylea (ectoparasitic flukes). In: Marine Parasitology (ed. by K. Rohde), Melbourne, Australia, pp. 63-72. CABI

81. Wootten R (1974) The spatial distribution of Dactylogyrus amphibothrium on the gills of ruffe Gymnocephalus cernua and its relation to the relative amounts of water passing over the parts of the gills. J Helminthol 48(3):167-174

82. Zelmer DA, Arai HP (1998) The contributions of host age and size to the aggregated distribution of parasites in yellow perch, Perca flavescens, from Garner Lake, Alberta, Canada. The Journal of parasitology, 24-28

\section{Figures}



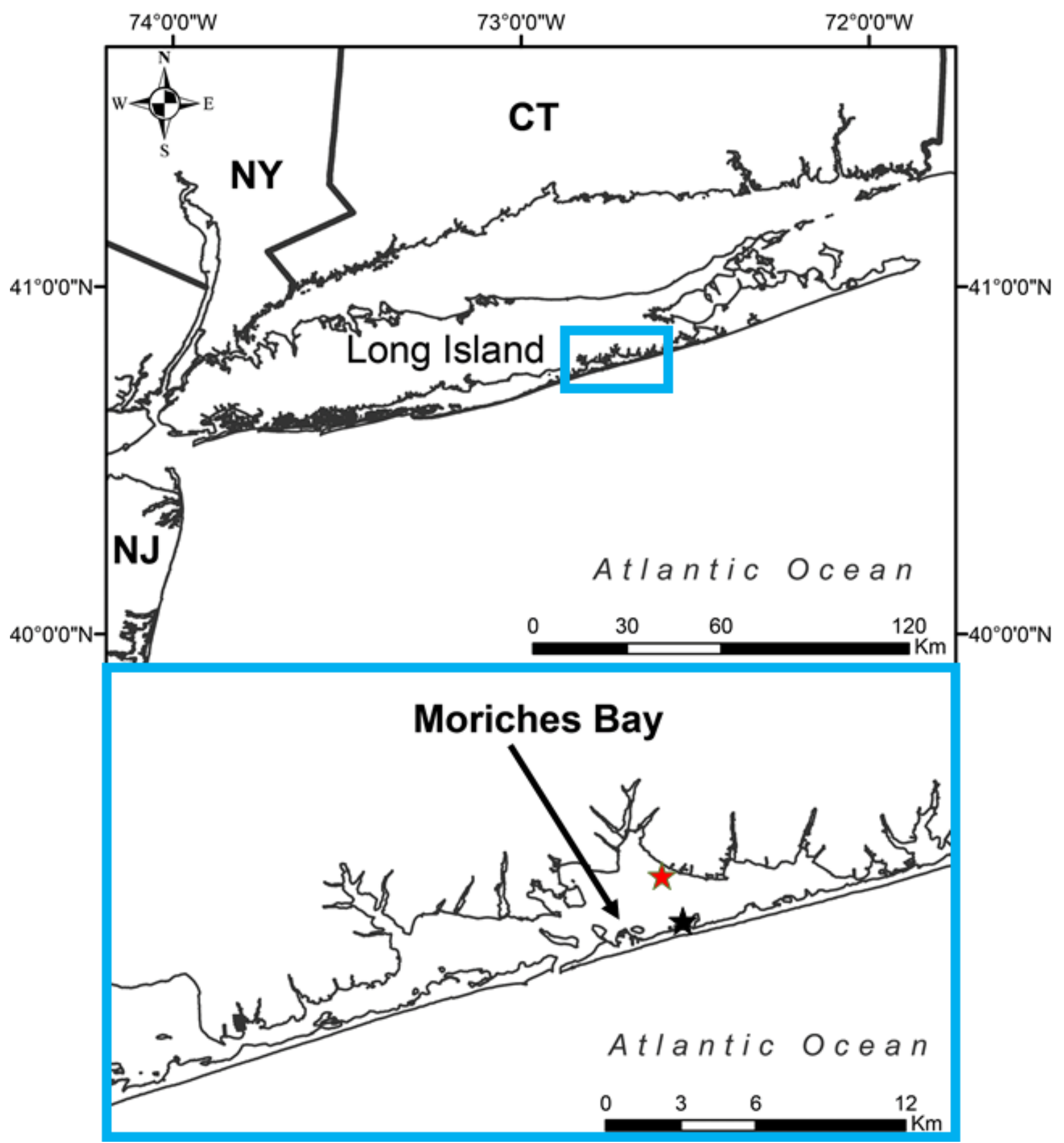

Figure 1

Map of Moriches Bay in Long Island, NY, USA. The black star represents Pike's beach, the intertidal sampling location for juvenile and adult crabs 2019. The red star denotes the trawl survey location where sub-adult crabs were opportunistically sampled in 2020. (Base map source: NOAA, ESRI) 


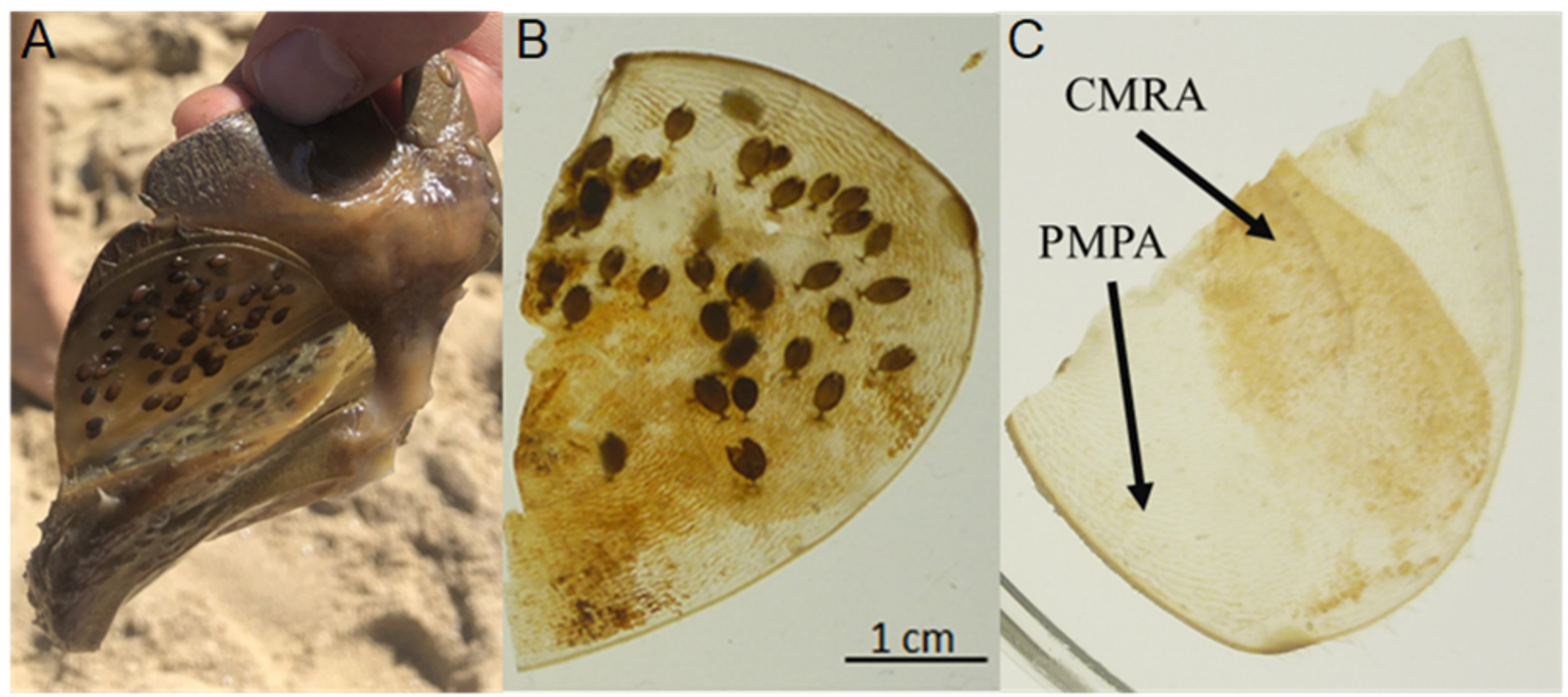

Figure 2

A) Book gill (10\%) removed from an adult horseshoe crab, in which the ventral most lamellae is heavily infected with B. candida cocoons. B) an individual gill lamella with moderate B. candida infection (>25 cocoons). C) The central mitochondria-rich area (CMRA) is located within the mid-section of the lamellae and has a darker pigmentation relative to the more transparent peripheral mitochondria-poor area (PMPA).

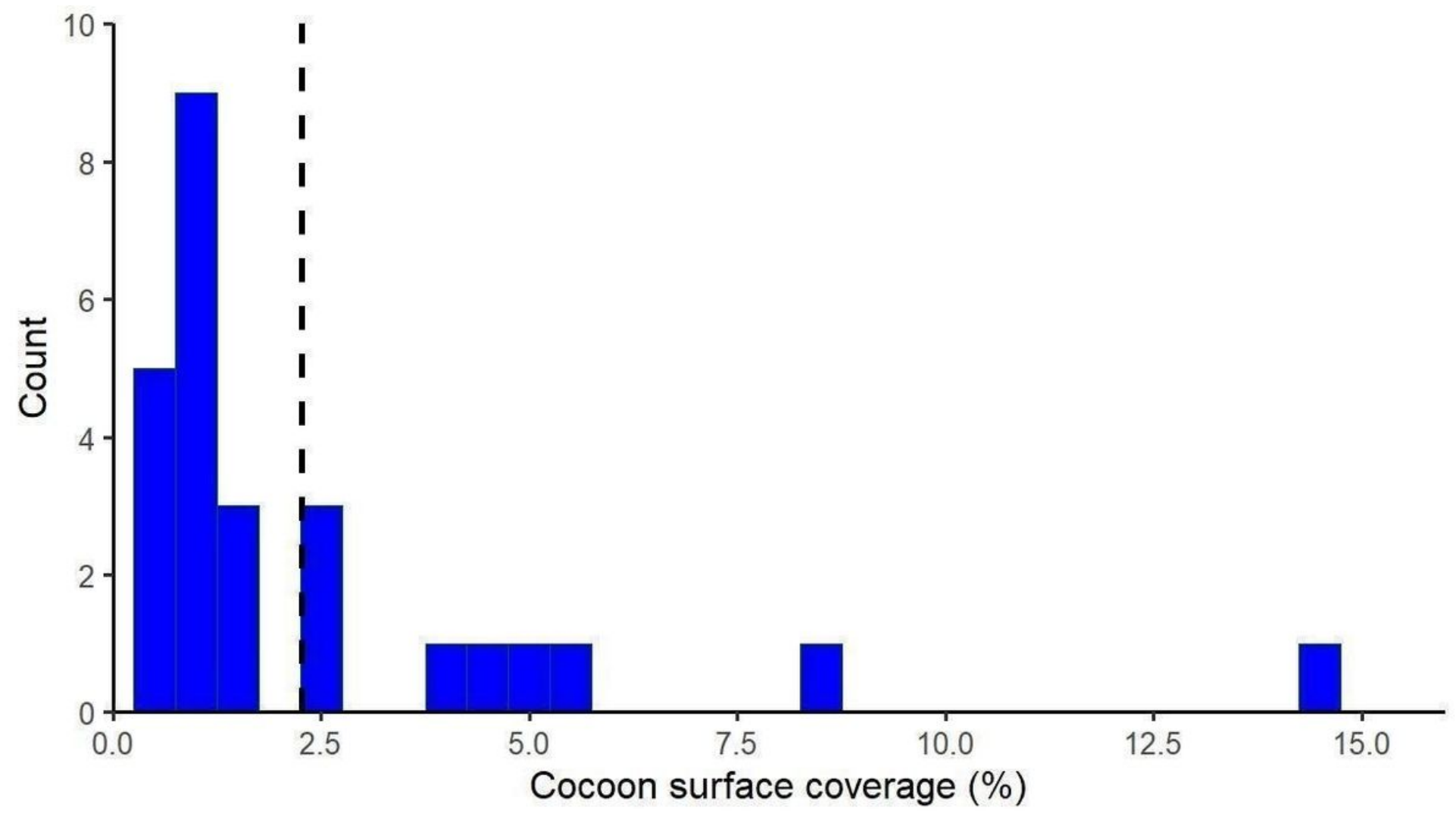


Figure 3

Histogram of the percentage of gill surface area covered by cocoons in infected adult horseshoe crabs $(n=29)$. The vertical dashed line represents the average.

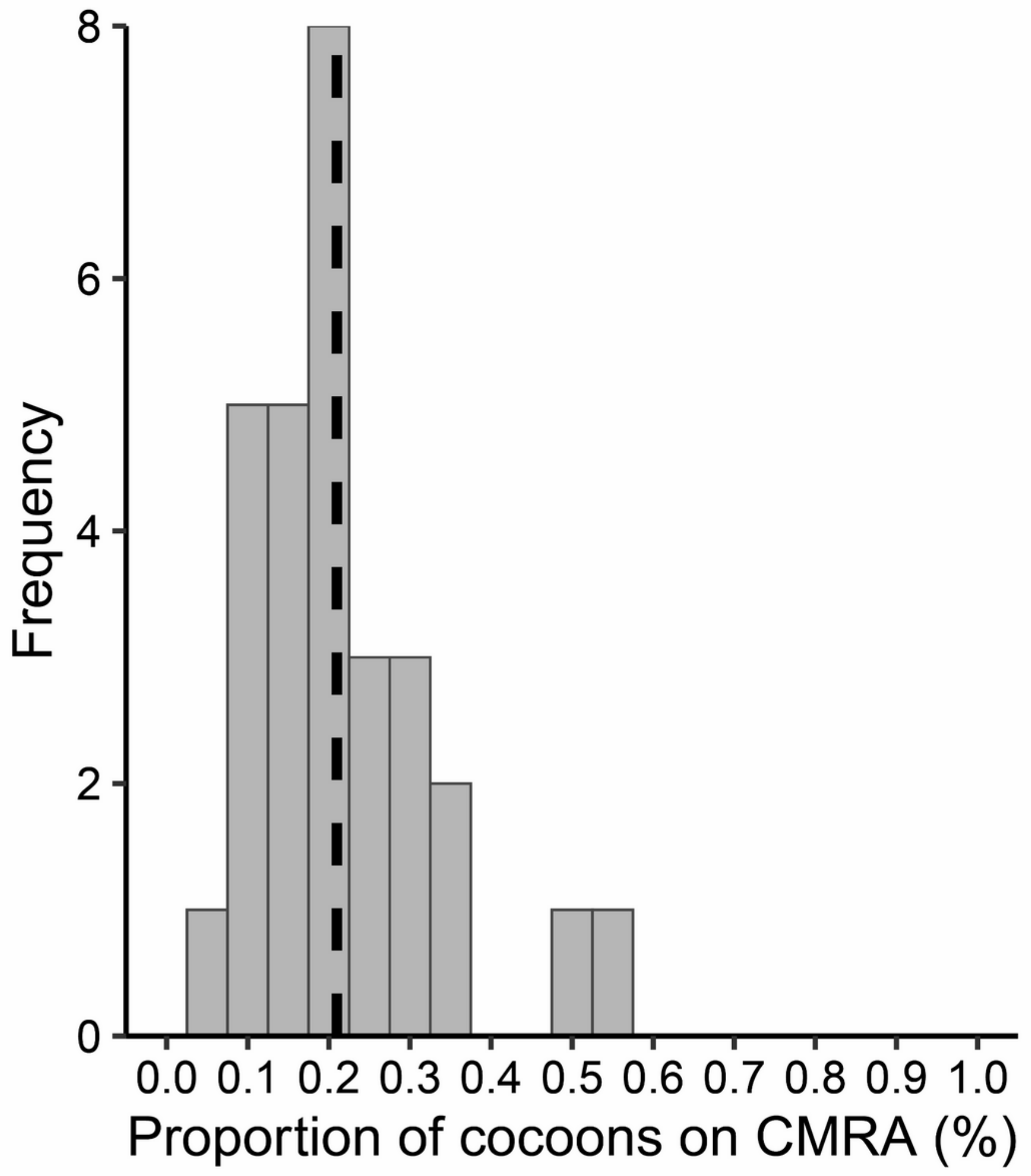

Figure 4 
Histogram showing the proportion of B. candida cocoons within the central mitochondrial-rich area in the gill lamellae $(n=29)$. Vertical line denotes the mean proportion of cocoons on CMRA $(0.21 \pm 0.02$ SE).
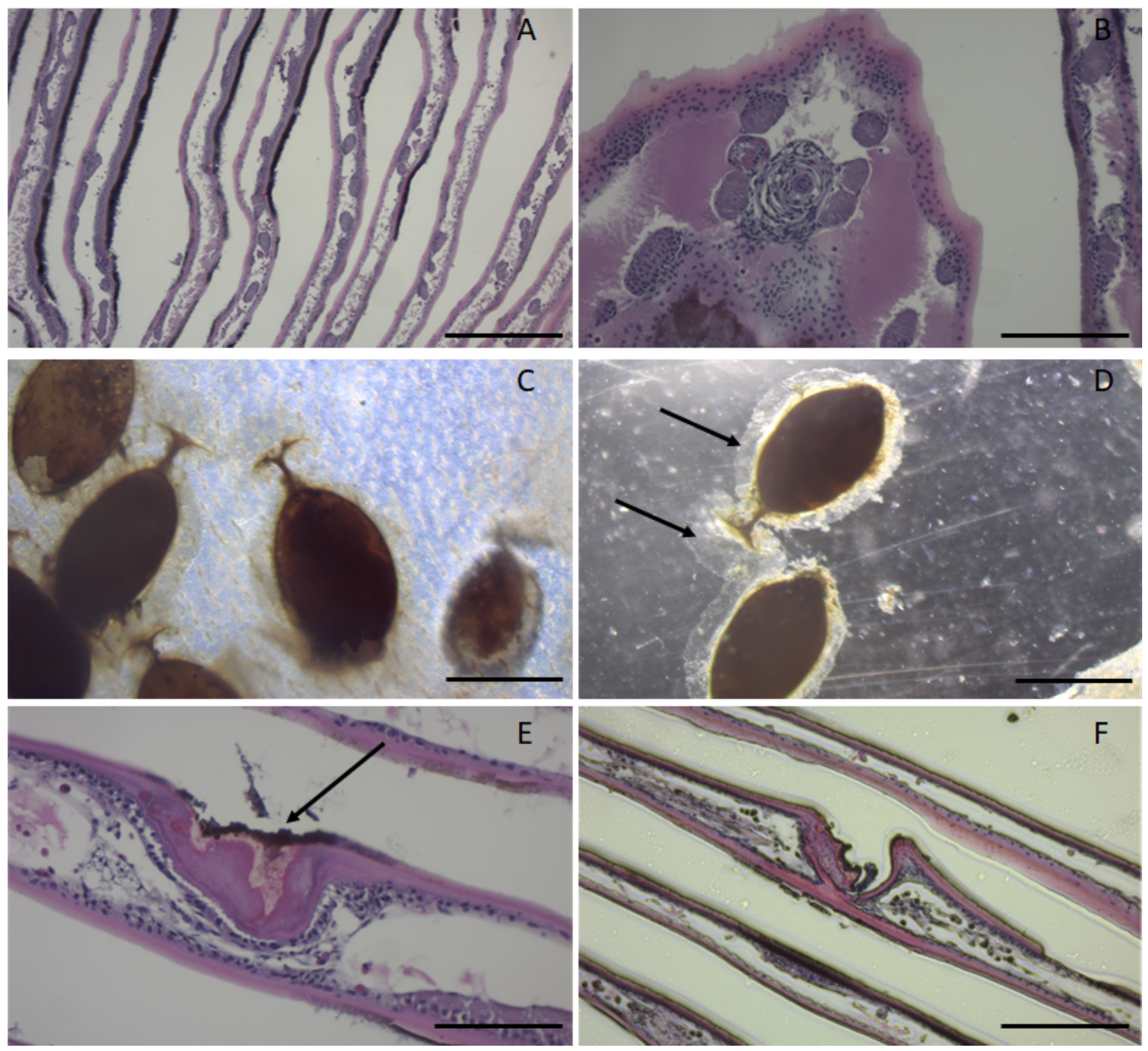

\section{Figure 5}

A) Normal gill histology of gills from an area not impacted by B. candida cocoons, nonpathogenic biofilms are present on the acellular layer of the chitinous epithelium stained black (scale bar $=500 \mu \mathrm{m}$ ).

B) Granuloma present in lamellae with intense hemocyte infiltration and inflammation (scale bar= 200 $\mu \mathrm{m})$. C) B. candida attached to a lamellae (scale bar= $1 \mathrm{~mm}$ ). D) B. candida removed from a lamellae with adhesion substance surrounding the cocoons and pointed out with arrows (scale bar $=1 \mathrm{~mm}$ ). E\&F) stained cross-section of a wound caused by B. candida, melanization was observed (arrow) with Loading [MathJax]/jax/output/CommonHTML/fonts/TeX/fontdata.js 
hemocytes aggregating along the inner surface of the epithelial layer (E scale bar $=100 \mu \mathrm{m} ; \mathrm{F}$ scale bar= $200 \mu \mathrm{m})$
A
B
C
D

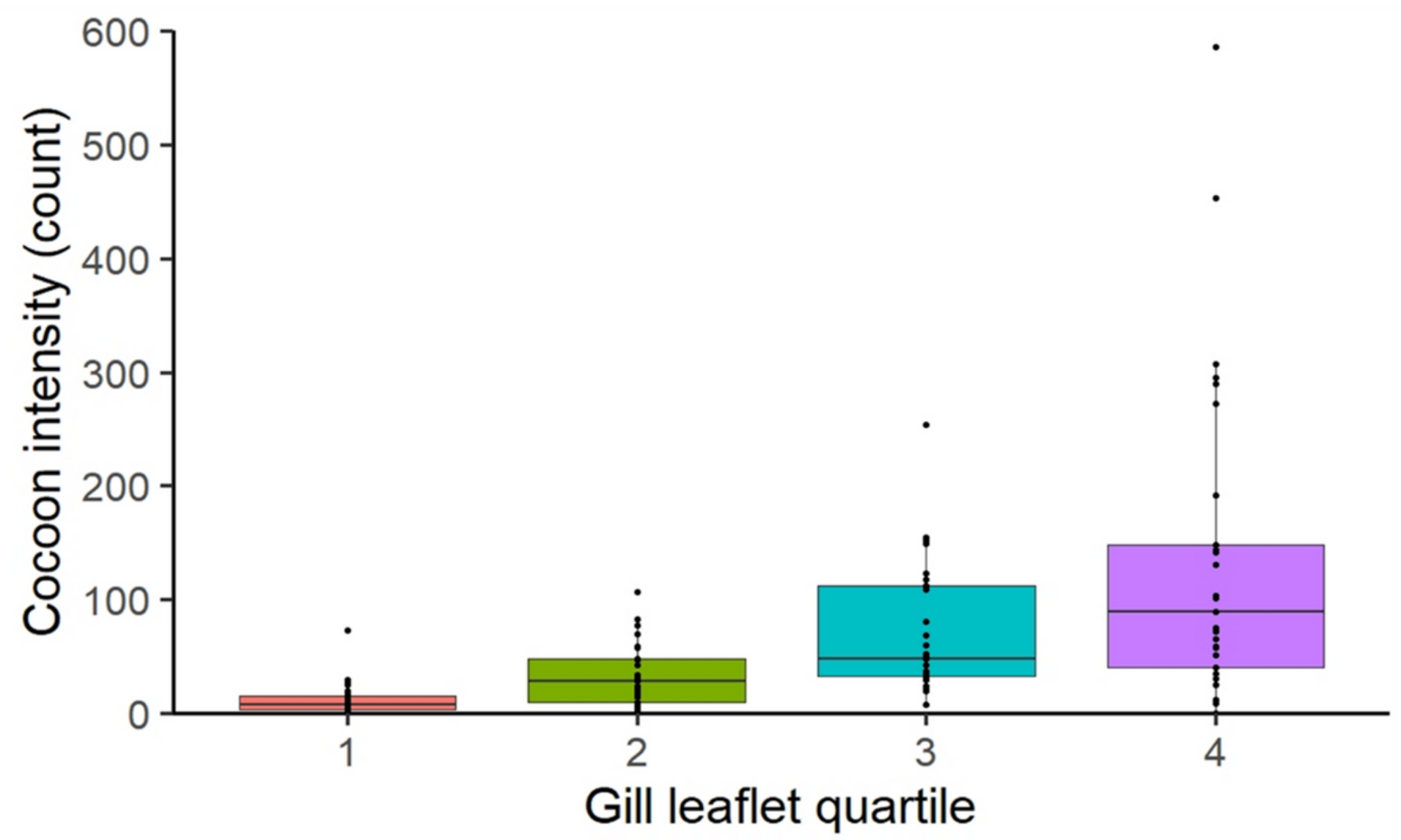

Figure 6

B. candida cocoon intensity for four gill lamellae quartile groups. The first quartile represents the dorsalmost gill lamellae; in contrast, the fourth quartile represents the ventral-most gill lamellae. Letters represent statistically significant differences between gill lamellae quartile groups from Conover post-hoc pairwise comparison tests shown in Table 3. Black dots represent each individual horseshoe crab's cocoon intensity in each gill lamellae quartile. 


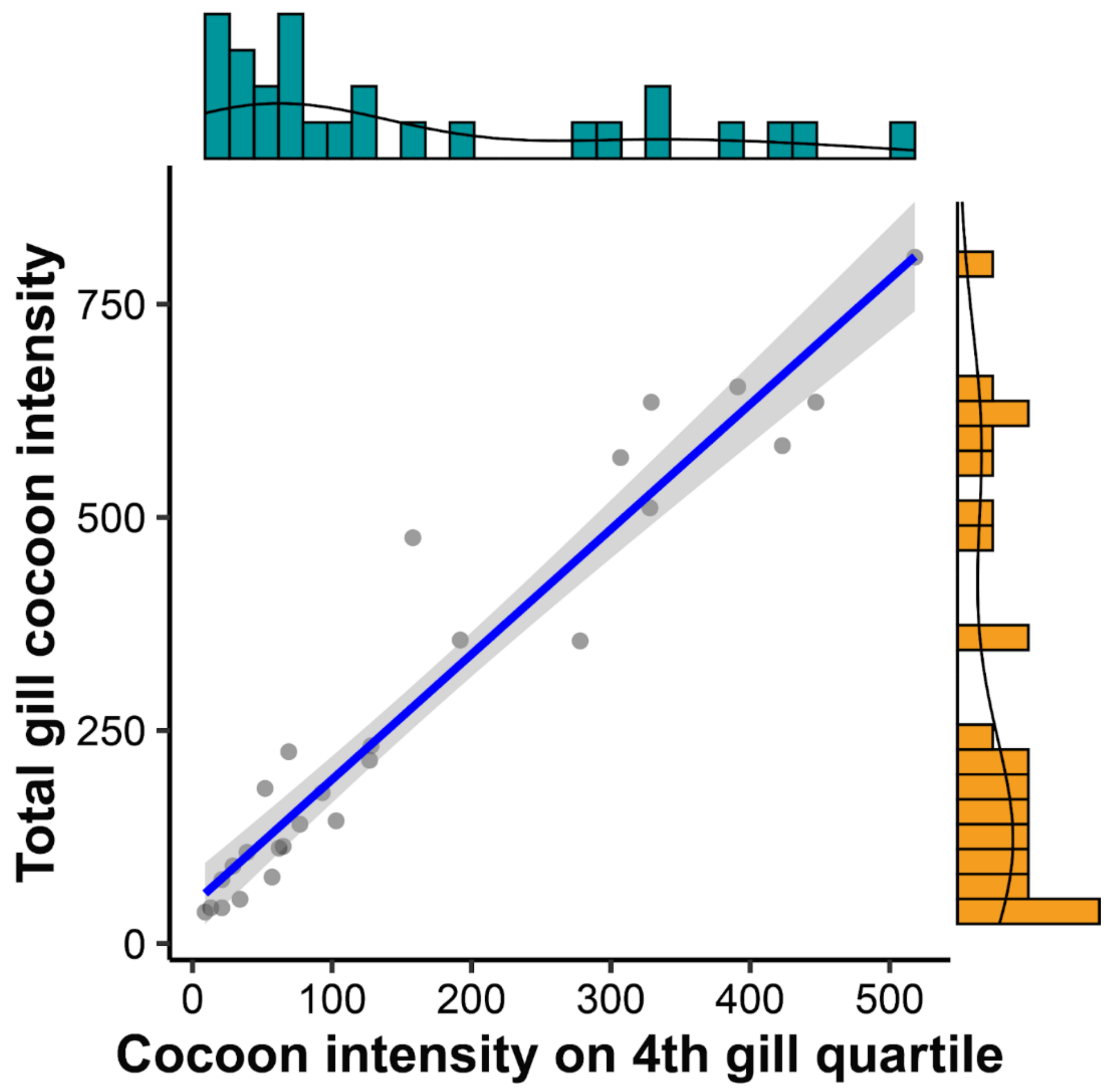

Figure 7

Scatter plot of cocoon intensity from the 4 th quartile of gill (ventral-most) leaflets $(n=27)$ vs. total gill cocoon intensity. The Spearman rank correlation results were: $p=0.96$ and $p=<0.001$. Standard error is represented by grey shading.

\section{Supplementary Files}


This is a list of supplementary files associated with this preprint. Click to download.

- figS1..png 